\title{
RECONVERSIÓN Y CONSERVADURISMO POLÍTICO EN BRASIL: los límites del cambio
}

\author{
Miguel Serna*
}

Resumen: El artículo aborda los cambios políticos recientes de la democracia y los partidos políticos de Brasil desde una perspectiva histórica comparativa. La hipótesis central es que para explicar la naturaleza y límites de los cambios electorales hay que comprender las dificultades históricas de los procesos de democratización y el peso de una matriz sociopolítica conservadora. En la primera sección se analiza la formación de una matriz sociopolítica conservadora y las debilidades de la democratización entre 1945 y 1964. En la segunda sección se aborda la dinámica de la democracia y los partidos políticos en las últimas dos décadas para identificar los límites de los cambios políticos electorales recientes.

Palabras clave: democracia, conservadurismo, partidos políticos, cambios políticos.

El triunfo de una coalición política liderada por un partido de izquierda en Brasil para las elecciones nacionales de 2002 abrió un amplio espectro de expectativas con respecto a los cambios políticos y sociales en dicho país y sus impactos hacia la región.

¿Cuáles son los cambios que se están produciendo?, es, por cierto, una pregunta difícil de responder y que ha generado una fuerte polémica durante el primer año del nuevo gobierno que continua hasta el final del mandato. Por una parte, se han alzado voces críticas desde la propia izquierda sobre las insuficiencias de las reformas sociales y la continuidad de las políticas pasadas

\footnotetext{
* Professor do Departamento de Sociologia da Facultad de Ciencias Sociales e da Facultad de Ciencias Económicas y de Administración da Universidad da República - Uruguai; doutor em política comparada e integração latino-americana pela Universidade Federal do Rio Grande do Sul - Brasil. E-mail: miguel@fcs.edu.uy Artigo recebido em 13 fev. 2005; aprovado em 3 nov. 2005.
} 
impulsadas. Para el centro político antes controlado por el sector del ex presidente Fernando Henrique Cardoso la oposición y el gobierno se ha desfigurado. Por otra parte, los sectores más conservadores han criticado la intensificación de la movilización y conflictos sociales en tanto amenaza del status quo.

¿Porqué tanta polémica?, ¿cuáles han sido los impactos de los cambios políticos electorales para la democracia brasileña?, ¿porqué la sensación de importantes resistencias a dichos cambios?

No es sencillo responder estas interrogantes hacia el futuro, no obstante, el objetivo de este trabajo es más modesto y acotado abordando dicha problemática mirando hacia el pasado; cómo ha sido la forma de construcción de la democracia brasileña y el sistema partidario para comprender tanto las limitantes históricas de la misma como de los impactos de las transformaciones recientes.

Para alcanzar dicho objetivo hay que explorar mas allá de la coyuntura e identificar qué factores y procesos de largo y mediano plazo influyeron en tal sentido. Preguntarse sobre las dificultades de los cambios supone mirar en una perspectiva de largo plazo, las restricciones provenientes del legado histórico de la construcción democrática en Brasil. En función de ello se abordará en la primera sección, la denominada matriz sociopolítica conservadora, y las debilidades del antecedente de democratización durante el período entre 1945 y 1964.Responder acerca de la naturaleza y efectos de los cambios de la democracia contemporánea supone un análisis de las transformaciones sociales y políticas de los partidos en las últimas dos décadas, la cual será analizada a partir de la segunda sección del artículo.

La perspectiva de análisis utilizada será desde la sociología política histórica (Serna,1998). Esto significa, destacar la utilización de la variable temporal en tanto variable de control y a ser explicada. Esto quiere decir recuperar la historia "real", en claves sociológicas, partiendo del supuesto que las sociedades, las experiencias de construcción institucional o de conflicto social no se realizan (ni se destruyen) de un momento a otro, que poseen cierta temporalidad vital, con sus ciclos, desarrollos y rupturas. 
Asimismo, se destaca el análisis de las trayectorias de construcción histórica de las democracias, para entender tanto la peculiaridad de éstos regímenes políticos como los condicionantes y contextos sociales que explican su génesis y desarrollo. En éste sentido, la formación de las instituciones políticas no puede reducirse a determinismos estructurales, sino que requiere entender la combinación entre las condiciones estructurales de la sociedad, los procesos políticos y la volundad de los sujetos colectivos. Se asume también que la acción colectiva, la reconstrucción de los sujetos históricos y el cambio social tienen una gama de "imprevisibilidad" y "potencialidad", a partir de las alternativas objetivas dadas por las condicionantes estructurales que producen un efecto de innovación en cada tiempo histórico concreto.

\section{Los orígenes de una matriz sociopolítica conservadora}

El nacimiento del pensamiento político conservador se remontó al momento de creación de la nación brasileña, proceso histórico que combinó una independencia conciliada y un régimen político basado en un liberalismo conservador. El proceso de independencia nacional de Brasil no se produjo en forma de ruptura violenta, como en el resto de las colonias españolas americanas, sino a través del propio gobierno metropolitano portugués que va a sentar las bases de la autonomía brasileña, con fuerte influencia debido al traslado de las instituciones monárquicas portuguesas en Brasil y que va alimentar la reproducción del conservadurismo en la etapa fundacional del país.

El pensamiento político brasileño fundacional se nutrió de dos vertientes teóricas entre el pensamiento monárquico colonial portugués y el elemento nacional republicano que quería romper con la supremacía portuguesa. Ambas vertientes llevaron a cabo una transacción o conciliación en el período de la independencia (Faoro, 1994, cap.5). El conservadurismo de la elite dirigente tuvo una visión más pragmática que el liberalismo de la época, fue una ideología adaptada a las circunstancias socioeconómicas de Brasil. 
Las reformas de las instituciones eran concebidas para conservar el orden político más que para cambiarlo (Mercadante, 1965, Cap. $\mathrm{XV}$ ). La importación de un liberalismo conservador -continuador de la tradición monárquica- fue lenta, progresiva a lo largo del tiempo, y en convivencia con prácticas autoritarias (Trindade, 1985). El "ethos" liberal en la política brasileña no superó su sesgo conservador. Imbuido por la ideología monárquica de la elite política y por la conformación de un estado centralista excluyente, favoreció las "actitudes de rechazo ante la participación popular" y el bloqueo a la expansión democrática.

La conformación de un Estado burocrático patrimonial fue otro factor que contribuyó al conservadurismo, siendo un condicionante relevante para la configuración de las instituciones políticas. La constitución de un "estamento burocrático" originario de una burguesía industrial y comercial que no fue capaz de emanciparse del Estado y mantuvo una relación patrimonialista dependiente del Estado nacional (Raymundo Faoro, 1979, p. 202, 205 y 221). La extensión del estamento burocrático se realizó por medio de los aparatos burocrático-políticos que se entrelazon patrimonialmente con los intereses locales y de los propietarios rurales a través de diversos mecanismos de cooptación y control políticos-administrativos.

Otra variable clave para entender la matriz sociopolítica conservadora fue el carácter elitista de la política brasileña fundacional. Uno de los aspectos señalados en la literatura ha sido la composición y formación de la elite dirigente en la etapa fundacional del Estado nacional (Trindade, 1986, p.143). Brasil nuevamente fue un caso que contó con una elite política sumamente homogénea y unida (Carvalho, 1996, p. 34) desde el punto de vista de su socialización educativa y de los perfiles sociopolíticos de los dirigentes que mantuvieron la continuación de los lazos con su la antigua colonia portuguesa.

La fase de instauración de la República mantuvo en buena medida este sesgo elitista en la construcción de la política. La 
República estuvo permeada de nuevas doctrinas positivista y militarista, pero con un ausencia de componentes liberales ni de soberanía basada en el pueblo como sujeto. La debilidad democrática se expresó en una ciudadanía restringida por criterios de capacidad educativa (exclusión de los analfabetos). Ello significó una participación limitada al 1,5\% de la población que era a su vez la que tenía los controles del poder económico.

Otro factor decisivo en el proceso de conformación de la República fue el modo de profesionalización del Ejército y su influencia en la política. En Brasil se produjo una profesionalización y politización tardía en la etapa de construcción fundacional del Estado nacional (Uricochea, 1978), jugando un papel crucial en la política post-imperial, integrándose como uno de los sectores dirigentes y asimismo cumpliendo un rol de moderación o árbitro en las disputas inter-elites políticas por el poder estatal.

Un rasgo recurrente en los análisis de las relaciones entre política y sociedad fue la perversa simbiosis entre espacios público y privado, resultado de una formación política nacional irregular e imperfecta, en la que confluyeron diversos factores. La extensión geográfica sumado a la discontinuidad territorial y social favoreció el profundo espíritu privado y patriarcal de los ámbitos locales. El monopolio de la función pública por la propia clase señorial terrateniente que representaba la organización privada local tuvo como resultado la feudalización del mando político comunal. El estado convivió pues con una tensión antagónica entre la legalidad escrita formal y la concepción doctrinaria personal del gobernante y los dirigentes políticos que imprimieron su sello y moldearon las instituciones pólitcas (Duarte, 1966, cap. VI).

La zonas grises de la articulación entre ámbitos públicos y privados, se manifestó también en la reproducción de mecanismos clientelares de dominación parroquial tradicional de base rural. Paradójicamente estos mecanismos se acoplaron a las nuevas formas de participación ciudadana, combinando mecanismos autoritarios y democráticos. Esto se manifestó en diversos planos, particularmente 
en la articulación entre elecciones nacionales a cargos ejecutivos, con elecciones estaduales y municipales, donde se tejieron múltiples compromisos con los jefes políticos locales (Leal, 1993). El "coronelismo" fue un mecanismo adaptativo de sobrevivencia y reproducción política de las oligarquías terratenientes agrarias frente a los cambios de urbanización e industrialización de la sociedad.

La maquinaria tradicional de la política de clientelas de base local se reconvirtió y extendió progresivamente incorporándose a las formas pluralistas de representación política desde 1930 en adelante, no sólo en ámbitos rurales, sino que también se reprodujo en espacios urbanos en tanto mecanismo burocrático patrimonial en beneficio de las clases medias emergentes. Desde el municipio al Estado federal, fue mecanismo de control político ampliado hacia un clientelismo a escala masiva. Las prácticas clientelísticas se reproducían paralelamente a la movilización de la participación política como mecanismo de control, tutela y dependencia de lealtades electorales por medio de intercambio de favores de recursos de poder público y burocrático. La negociación personal clientelar involucraba la distribución selectiva de una amplia gama de recursos estatales, de empleo, de provisión de servicios públicos y de regulación de intereses particulares.

De esta forma la democracia coexistirá con dos principios en la organización política de tipo patrimonial burocrático: la representación y la cooptación (Schwartzman, 1982, Cap.6 ), que se expresaban en mecanismos contrapuestos y convergentes en las relaciones entre Estado y sociedad civil.

El desarrollo político hacia formas institucionales en que prevalecían mecanismos de cooptación provino también de los procesos de centralización estatal y de la ideología autoritaria estatista, antiliberal y antipartidaria de la herencia del Estado Novo.

Las formas neopatrimoniales del estado fueron resultado de diversos procesos de centralización y descentralización del poder estatal que no se redujeron a los márgenes de maniobra de los ámbitos estadual y municipal, sino también al papel clave que jugaron los 
conflictos entre distintas regiones sociopolíticas en la organización y dinámica del sistema político a lo largo de la historia brasileña. ${ }^{1}$

El ciclo histórico 1945 a 1964 es el antecedente más reconocido de la formación de una democracia de masas, proceso político que se produce de forma paralela a una serie de transformaciones estructurales de la sociedad y la economía brasileña.

Desde la década del 40' comienzan a gestarse una serie de cambios de largo plazo que expresarán una modernización lenta y controlada de la sociedad y una institucionalización democrática débil. En 1940 apenas el 16\% de la población vivía en ciudades de más de 20 mil habitantes. A inicios de la década del 50 la tasa de urbanización era de 30,7\%, hacia 1960 la proporción de la población en centros urbanos se eleva al $40 \%$. De esta forma se manifestaba una modificación progresiva de la estructura social, disminuyendo su peso agrario tradicional y emergiendo nuevos sectores sociales. El denominado desarrollo económico "hacia dentro" se dió a través del proceso de sustitución de importaciones, desde de los bienes de consumo no duradero hasta los bienes de capital de los años 50 a $\operatorname{los} 60$.

La extensión del sufragio y de la participación ciudadana efectiva expresó un proceso de fuerte impulso a la movilización política y al establecimiento de la competencia electoral como mecanismo de disputa de elencos políticos y distribución de cargos de gobierno entre los diversos partidos. Le evolución de la convocatoria ciudadana en elecciones fue muy significativa. Hasta 1930 la participación general en elecciones no superaba el 3,5\% de la población, a partir de 1945 el electorado se expande al 13,5\% y para 1962 alcanza al 18,4\%. La creciente movilización política, significó la ampliación e integración de nuevos grupos que se fueron incorporando a la arena política. No obstante, una de las restricciones relevantes a la misma fue la exclusión de analfabetos del derecho del sufragio.

La canalización de la participación política se dio paralelamente a la institucionalización y funcionamiento de las reglas 
e instituciones políticas de la democracia representativa liberal. La tardía conformación partidaria, tuvo sus condicionantes en el desarrollo previo de estructuras políticas pautadas por la fortaleza del Estado nacional previo al surgimiento del sistema partidario como una variable central para entender las dificultades y obstáculos en la institucionalización de la dinámica partidaria nacional. El estudio ya clásico de María do Carmo Campelo de Souza (1976) analizó con detalle la influencia condicionante de los mecanismos estatales de centralización burocráticos y del gobierno federal en la cohesión organizativa de los partidos en el nivel nacional.

Se ha señalado recurrentemente como características destacables del sistema partidario su debilidad institucional en términos de precariedad, fragilidad y fragmentación interna, así como la discontinuidad temporal de las organizaciones partidarias. ${ }^{2}$ En este sentido, uno de los contrastes más peculiares del sistema político brasileño fue la combinación de una larga continuidad en el funcionamiento de las instituciones parlamentarias y los mecanismos electorales para la selección de elites, con una discontinuidad contrastante al nivel de las organizaciones partidarias.

En función de todos los elementos previos es un punto común en la literatura afirmar que un sistema de partidos nacional diferenciado se desarrolló después del golpe de estado de $1945 .^{3} \mathrm{~A}$ medida que se sedimentaban los patrones de competencia electoral, aumentaba la identificación política de la ciudadanía con los partidos, expresada en una mayor congruencia entre las actitudes de identificación política partidaria y las intenciones de voto (Lavareda, 1991, p. 21).

Otro rasgo destacable en la configuración del sistema de partidos fue la articulación de los ámbitos nacionales con una serie de subsistemas regionales estaduales (Lima Jr., 1983) a partir de los cuáles se tejieron diversas alianzas partidarias - estaduales y nacionales - siguiendo una racionalidad contextual en el tiempo y espacio de acuerdo a la proximidad ideológica y al tamaño de los partidos. De esta manera la conformación de partidos nacionales 
convivió con la representación de intereses y pautas políticas regionales.

El sistema electoral por su parte, reforzó algunas pautas de la política brasileña. De un lado, la combinación del sistema mayoritario para cargos ejecutivos y proporcional para cargos legislativos priorizando fue acotado al interior de las unidades estaduales (Kinzo, 1980, p.127), lo cuál tuvo efectos de desproporcionalidad de los Estados miembros de la Federación sobrerepresentando el peso de los más pequeños y subrepresentó a los más grandes. De otro lado, la adopción del sistema de lista abierta para la presentación de candidatos lo que otorgó una influencia enorme al elector para la determinación del orden de interno de los partidos. La autonomía de los candidatos respecto a las máquinas partidarias estuvo favorecido por una gran cantidad de incentivos a las carreras políticas individuales, la personalización de la representación y la reproducción de la mecanismos clientelísticos (Mainwaring, 1991, p. 9-10).

El legado populista ${ }^{4}$ tuvo consecuencias múltiples y ambiguas sobre el desarrollo democrático del período. El pacto populista se apoyaba por una parte en un modelo de desarrollo hacia dentro por medio de la industrialización por sustitución de importaciones y la expansión del mercado interno con un papel impulsor del Estado central, gestada desde la revolución del 30 en el denominado Estado Novo. Por otro, articulaba una alianza entre la burguesía industrial, las clases medias, y el proletario urbano, con un sector agroexportador y de militares nacionalistas. A los elementos estructurales y sectores sociales, se sumaba el papel de simbiosis simbólica y personal en el liderazgo carismático de Getulio Vargas.

El lado negativo del legado populista en la política brasileña estuvo relacionado al carácter estatista y anticipatorio cupular de la movilización popular. Se interpretó pues como un proceso político de incorporación de las masas populares controlado de "arriba para abajo" por la nueva clase dirigente del Estado Nuevo (Bodea,1992, p. 203). 
La dependencia personal del destino del líder, se reforzaba por la falta de autonomía de las organizaciones sindicales de la estructura del Estado, trasladando los atributos de una persona a una forma estatal, y un tipo de movilización política (Weffort ,1980, p. 193).

La ambivalencia ideológica del proyecto populista y trabalhista consistió en que por una parte buscaba organizar y movilizar al proletariado para integrarlo a la estructura social como medio de mejora de la justicia social. Por otra parte, postulaba la intervención del Estado en tanto agente articulador de un compromiso social que asegurara la "integración armónica de las clases productoras" con el progreso económico y social (Bodea, 1992, p.185), constituyéndose en medio de arbitraje y neutralización del conflicto social. La polémica con respecto a la ambivalencia de las "interpelaciones nacionalpopulares" al decir de Laclau, tuvo consecuencias e interpretaciones diversas. Una de ellas fue posibilidad del "autoritarismo democrático" (Bodea, 1992, p.206) para interpretar la simbiosis del liderazgo carismático de líder Vargas antes identificado con el Estado, luego reconvertido en un liderzazgo plebiscitario dentro de la democracia liberal pluralista.

Las ambivalencias del legado populista se observaron también en la evolución del desempeño electoral entre ambos partidos. El decaimiento del modelo nacional populista, fue en parte erosionando las bases sociales del PSD que se expresó en un claro descenso de caudal electoral a inicios de los 60'. Mientras en 1945 el PSD controlaba el 52,8\% de las bancas de la cámara federal, en 1962 su representación parlamentaria se redujo a un 30,3\% (Souza, 1976, p. 144), a lo que se sumó la fractura de la coalición con el PTB en la elección de Janio Quadros.

En sentido inverso, el PTB se fue progresivamente radicalizando a inicios de los 60' y enraizando cada vez más fuerte su capacidad de movilización popular urbana. Esta participación popular se expresará en una fase de crecimiento electoral acentuado (Lavareda, p. 89). En 1945 contaba con una bancada parlamentaria en 
la Cámara Federal de 7,7\%, en tanto hacia 1962 alcanzó a controlar el 29,8\% de las bancas (Souza, 1976, p. 144).

En contraste al progresivo proceso de modernización de la estructura social, de pluralización de la representación partidaria, así como de participación política y movilización social cada vez más autónoma, el golpe de estado de 1964 interrumpió el desarrollo de la democracia de masas. La suerte de la democracia se quebró frente a un autoritarismo precoz que tuvo múltiples consecuencias, que van a expresar algunas de las principales restricciones al desarrollo político del período.

La irrupción militar tuvo un carácter restaurador del orden (O’Donnell, 1997) frente a la percepción de los sectores conservadores de amenaza de quiebre del statu quo ante la emergencia de la movilización popular, y la necesidad de "normalización" de la economía. Esta percepción por parte de los sectores conservadores de inestabilidad política y vacío de poder no se explicaba sólo por el cuestionamiento del desarrollo capitalista, sino también por la sensación de amenaza de cambio del núcleo de la estructura agraria tradicional. Los sectores de la estructura agraria tradicional se percibían temerosos en sus fuentes de poder tanto por la movilización de los sectores subalternos rurales como por los requerimientos de un nuevo impulso a la capitalización y modernización del agro.

Otra consecuencia de la instauración del régimen autoritario a partir de 1964 fue el fortalecimiento del centralismo estatal. La intervención militar asumió un papel moderador (Stepan) autoproclamándose en tanto guardianes del statu quo representado en el estado nación.

El quiebre de las instituciones políticas significó una ruptura en las formas de representación pluralista, la desestructuración de los actores y organizaciones partidarias nacionales previas. En contrapartida, se produjo una reestructuración de los formatos representación política combinando un régimen de gobierno 
autoritario con algunas instituciones representativas restringidas en sus funciones ${ }^{5}$ y cohabitando con canales estatales de cooptación y mediación de intereses.

\section{Una democracia liberal de masas con desigualdades persistentes}

La construcción de la democracia brasileña en los últimos 20 años debe comprenderse en el marco de cambios de largo y mediano plazo en las relaciones Estado y sociedad. Las transformaciones de la sociedad y democracia brasileña pueden ser analizada en tres planos o dimensiones, en lo que refiere al modelo de desarrollo económico, a la formas de estructuración de alianzas políticas de gobierno y en relación a la movilización de nuevos actores colectivos.

Desde la década del 70 al 80 se produjo un acelerado proceso de desarrollo económico que constituyó a Brasil dentro de las naciones consideradas como potencias emergentes a nivel mundial y con un liderazgo particular dentro de latinoamérica.

Esta transformación económica se produjo paralelamente a un proceso autoritario y controlado política y socialmente. No obstante, la apertura política a comienzos de los ochenta inició un proceso de movilización política y social del cuál va a emerger un nuevo formato institucional y de actores que darán lugar a una democratización sin precedentes en cuanto a extensión y representación alcanzada.

A pesar de la afirmación del proceso de democratización política y social el giro dominante hacia una liberalización económica en los noventa, implicó que la democracia emergente tuvo que convivir con el mantenimiento de desigualdades sociales persistentes.

A efectos del análisis más detallado de los cambios se identificará distintos subperíodos relevantes. El primero abarcó la década del ochenta, desde la reforma partidaria y convocatorias a 
elecciones competitivas en 1982 hasta la aprobación de la nueva constitución que culminó con las elecciones generales y abiertas de 1989. Los ejes del período pasaron por un doble recorrido, entre el declive y crisis del modelo de desarrollo articulado al Estado, y un proceso profundo de democratización política y social.

La disolución del formato bipartidista impuesto por el régimen autoritario desde 1968 y la reconstrucción de un sistema de representación pluralista fue resultado de una larga transición democrática. Este proceso 'lento' en cuanto a su duración temporal (de 1974 a 1985), 'gradual' en la forma de liberalización del régimen político, y 'controlado' desde la cúspide por los militares. Asimismo, los avances en las reglas de juego y demandas de participación fueron canalizados mediante el procedimiento electoral.

La apertura progresiva por la vía electoral fue viable en gran medida por la aceptación de la oposición a disputar una cuota de poder en el ámbito legislativo debilitado en sus potestades de acción y controlado dentro de las reglas formales impuestas por el régimen autoritario (Lamounier, 1988, p.123). De esta manera la transición adquirió un tipo de negociación implícita más que de salida negociada o pactada.

El punto de inflexión de la transición democrática en Brasil se produjó a partir del año 1979 donde el incremento de la fuerza política-electoral de la oposición y la reactivación de espacios de organización social de la sociedad civil presionaron para una apertura política que modificó los marcos del proyecto originario de liberalización tutelada.

El impulso hacia la apertura política, se producía en un trasfondo de profundos cambios en la estructura social resultado del fuerte desarrollo ecónomico de la década del 70' al 80'. Hacia 1980 Brasil dejaba finalmente la condición de sociedad rural, su población urbana alcanzaba al $51,1 \%$ de la población total. Asimismo, la población económicamente activa en el sector primario se redujo al 
$29,28 \%$ y también disminuyó la participación del sector al 12,3\% de las exportaciones. El nuevo ciclo de modernización y desarrollo se tradujo en cambios en la composición de los sectores de la economía. La contribución sectorial para el PBI que hacia 1950 era de un $24,1 \%$ del sector secundario y de $51,6 \%$ del sector terciario pasaron a aportar hacia 1985 un $34,4 \%$ y 55,8\% del PBI respectivamente.

Paralelamente, a estos profundos cambios sociales y económicos estructurales se producía un renacimiento de la sociedad civil organizada y la movilización de los actores populares reclamando mayor participación y atención a necesidades básicas insatisfechas. En este sentido, emergen nuevos actores colectivos, los sindicatos de trabajares urbanos, movimientos sociales urbanos y rurales en pro de mejores condiciones de vida para la población, y también movimientos de sectores intelectuales y de la cultura.

En este contexto, las elecciones de 1982 significaron el agotamiento del formato bipartidista impuesto por el régimen autoritario y el retorno a un sistema más pluralista en cuanto al número de partidos y en el peso de la oposición al régimen autoritario. ${ }^{6}$ Por un lado, las dos fuerzas políticas principales cambiaron de sigla, el MDB que aglutinaba a toda la oposición política se transformó en el Partido del Movimiento Democrático Brasileño, mientras que la antigua ARENA representante político del sector oficialista en el gobierno se constituyó en el Partido Democrático Social. No obstante, estos partidos no perderán su capacidad de canalización de las adhesiones políticas, reteniendo el $86 \%$ de las preferencias partidarias.

Por otro lado, surgieron tres partidos de oposición. Dos de ellos, se vincularon con la refundación y reinvención de la tradición "trabalhista" getulista. El clima de apertura política a partir de la Ley de Amnistía permitió el regreso del exilio y reorganización de los antiguos cuadros de dirigentes del Partido Trabalhista Brasileño. Sin embargo, la reorganización del antiguo PTB se hizo por medio de una división interna y de reinvención política. En parte, debido 
a viejas rivalidades entre janguistas y brizolistas, así como a los recelos que generó la sucesión de liderazgo político en Brizola, unido a una polémica decisión de la justicia a favor de mantener en manos de Ivete Vargas la sigla partidaria, catalizó una fractura entre los trabalhistas que tuvo como consecuencias la emergencia de un nuevo partido. La pérdida de la sigla partidaria disminuyó el impacto político de la refundación del PTB que dividió el peso de sus cuadros partidarios históricos ${ }^{7}$ y recolocó al PTB hacia el campo ideológico conservador.

La reinvención de un nuevo partido trabalhista se realizó con la fundación del Partido Democrata Trabalhista. La reconstrucción de la identidad trabalhista, se dio a partir de la convocatoria de Brizola, que se presentó en tanto líder histórico del PTB, reinterpretando la vigencia y continuidad del trabalhismo de Vargas. De esta manera, aparecieron banderas típicas trabalhistas, como la búsqueda del desarrollo y emancipación nacional amenazado por dos grandes enemigos la "oligarquía rural" y el "imperialismo extranjero"; y el trabalhismo en tanto movimiento de defensa de las clases trabajadoras y las fuerzas populares en oposición a las elites nacionales. Asimismo, emergieron nuevas temáticas, la opción por la democracia y el socialismo, interpretando al trabalhismo como un camino para la construcción del socialismo democrático; la valorización del pluralismo y la defensa de las minorías excluidas (énfasis en las cuestiones de género y etnia).

El tercer actor político en juego, el más nuevo fue el Partido de los Trabajadores (PT) nació a iniciativa de los poderosos sindicatos de trabajadores paulistas fundados a fines de la década del 70' conocido como "novo sindicalismo".

La originalidad en el espectro partidario fue dada por su origen que no residió en disidencias o recomposición de elites políticas pasadas sino en su carácter societario e ideológico autónomo de las clientelas y servicios del Estado. La peculiaridad de la estructura organizativa fue resultado de la conjugación de tres elementos 
estructurales: a) la iniciativa fundacional provino de los sindicatos de trabajadores, sectores de la intelectualidad y de la clase política en la oposición; y de parte de los movimientos sociales urbanos de la década del 70' y organizaciones de izquierda; b) la formación de una organización de partido de masa poderoso más allá de las instancias electorales; y c) un programa político con una ideología clasista que se proponía la reorganización del sistema político en la representación de intereses y participación de los sectores populares (Meneguello, 1989, p. 40-41).

El período entre las elecciones de 1982 y el traspaso del gobierno federal en 1985 estuvo pautado por una tensión entre las iniciativas del régimen autoritario de controlar cupularmente la sucesión del mandato presidencial vía indirecta por medio del Colegio Electoral y las posturas de los sectores más críticos de la oposición de ampliar los canales de participación ciudadana.

En éste contexto desde un sector del PMDB, el PT y partidos de izquierda organizaron una amplia movilización popular para la realización de elecciones directas para presidente, las "Diretas-já". La movilización no logró obstaculizar el acuerdo cupular para la designación del presidente sucesor al régimen, sin embargo fue una expresión de la demanda social por democratización de las estructuras políticas e inhibió la reacción golpista de grupos favorables a la continuidad del régimen (Arturi, 1995, p. 22).

Desde la elección de Tancredo Neves por parte del Colegio Electoral en 1985 hasta las elecciones generales por primera vez en forma directa del presidente en noviembre de 1989 fue un período donde se procesaron cambios que impactaron a largo plazo en el nuevo formato multipartidista.

Los primeros años de gobierno de la "Nova República" se desarrollaron en un contexto de crisis de múltiples dimensiones, ${ }^{8}$ la muerte sorpresiva de Tancredo Neves, la situación de crisis económica y la formulación de respuestas canalizadas en el Plano Cruzado. Las elecciones de 1986 reforzaron la legitimidad de la 
"Alianza democrática" (PMBD-PFL) que unificó a los sectores más conservadores (del PMDB y de los partidos del antiguo régimen) en el gobierno federal y la política de gobernadores estaduales. E1 PMDB obtuvo 22 de las 23 gobiernos estaduales y la mayoría absoluta en el parlamento federal. En estas elecciones también se produjeron algunas tendencias de cambios que se catalizarán en 1989, por un lado la fragmentación de los partidos de derecha, y por otro, el lento aunque progresivo crecimiento de partidos de izquierda (más notorio en el PT).

Las expectativas crecientes de temas sociales y económicos pendientes de la transición se trasladaron de la agenda gubernativa hacia la Asamblea Constituyente de 1988 con la finalidad de aprobar una nueva constitución. Esta conjugación de demandas y actores se canalizó hacia un proceso de democratización de las instituciones públicas desde 1985 a la constituyente de 1988 (Sallum, 2004, p. 284-286) y que se plasmó en múltiples reformas. ${ }^{9}$

Se destacó pues la reforma del sistema electoral, en especial en la elección presidencial. La consagración de elecciones directas a Presidente por sistema de mayoría absoluta de votos válidos en dos vueltas sustituyó el desgastado método de la elección indirecta a través de un colegio electoral. Además se redujo la duración del mandato presidencial de 5 a 4 años. Asimismo, se estableció la simultaneidad en las elecciones presidenciales con la renovación parcial del Congreso nacional y con las elecciones a cargos ejecutivos y parlamentarios estaduales. No obstante, se mantuvo la separación entre elecciones nacionales y estaduales de las municipales. También se consagró la elección directa para todos los cargos ejecutivos electivos, presidente y gobernadores de la Federación.

Otras reformas que tenían que ver con el sistema de representación, fueron la incorporación de la representación política del distrito federal y la garantía efectiva de libertad de organización de todos los partidos políticos.

Las reformas no se limitaron a los procedimientos de representación y elección de cargos políticos sino que también 
eliminaron restricciones y universalizaron la ciudadanía, incorporando por primera vez el derecho al voto de los analfabetos. Esta democratización de la base ciudadana se acompañó de una extensión efectiva de la participación electoral que pasó de $18,4 \%$ en 1960 a 52\% de la población para la década del noventa. De esta forma, la nueva república alcanzó niveles de participación política similares a los de Argentina, y el cono sur que ostentan de los grados de participación electoral más altos de América del sur.

La ampliación de los derechos ciudadanos, también se producieron en el reconocimiento de la capacidad autónoma de organización colectiva de las clases populares ${ }^{10} \mathrm{y}$ de múltiples derechos sociales.

En este marco, la Constituyente fue un espacio central para medir la recomposición y realineamiento de los partidos que se expresaron en las elecciones de 1989: la ruptura del PMDB y la creación del PSDB, el desprestigio de la clase política tradicional y el voto castigo al gobierno; la apuesta por candidatos que representaron la oposición a los valores del liberalismo conservador y la polarización de los partidos en el eje izquierda-derecha.

La reestructuración del sistema partidario quedó manifiesta en las elecciones de 1989. Los análisis mostraron que el voto castigo contra los políticos tradicionales conservadores se expresó en un apoyo a los candidatos presidenciales que se identificaron con la percepción de cambio y de superación de la injusticia, la exclusión y la desconfianza en las instituciones políticas (Sallum Jr, Graeffe, Lima, 1990, p. 71). Sin embargo la crisis de confianza partidaria no se expresó crisis institucional, sino que se canalizó a través de la migración de las fuerzas políticas hacia los polos de la izquierda y la derecha.

En la coyuntura los cambios más notorios fueron el vaciamiento del centro debido al quiebre del PMDB, el desgaste de la alianza oficialista entre el centro y la derecha PMDB-PFL y 
la aparición de nuevos partidos, la escisión el PSDB, y el impacto de la aparición del liderazgo carismático de Collor de Mello que reestructura a los sectores conservadores. El vaciamiento del centro fue sustituído por una competencia centrífuga a los extremos que polarizó las elecciones entre la derecha y la izquierda.

\section{Reformas neoliberales y reconversión de los actores políticos}

En contraste con los impulsos a la democratización de las estructuras políticas de los ochenta, la década del noventa se caracterizó por la reorientación dominante hacia implantación de reformas de liberalización económica y reforma del Estado (austeridad fiscal, privatización, liberalización de mercados). La dinámica política partidaria acompañará el ritmo y modo de estas reformas que se expresarán en realineamientos de las fuerzas políticas partidarias y la reconversión de los actores dominantes de la transición política. Por una parte, se expresará en la renovación populista elites tradicionales y por otra, la emergencia de una nueva oposición político social. Este realineamiento político ideológico, se expresará asimismo en cambios en la representación política y social.

El impulso populista-liberal no obtendrá réditos en términos de gobernabilidad y fue moderado en sus alcances con la salida de Collor de Mello y la inauguración del ciclo de liberalización social de los gobiernos de Fernando Henrique Cardoso de 1994 a 2002. Esto permitió nuevos avances en la liberalización del Estado con un estilo de implementación de reformas graduales de las reformas y con políticas sociales compensatorias. Al mismo tiempo, estos gobiernos aseguraron una estabilidad política basada en la recomposición de una alianza entre el centro y los partidos conservadores. La consolidación de esa alianza política se plasmó en la reforma electoral parcial de 1997 que permitió la reelección presidencial. 
Los logros económicos del plan Real y la articulación de una alianza política estable se verán enfrentados a las consecuencias de la crisis económica de 1999. Los costos políticos y sociales del programa de liberalización, la reforma del Estado y posterior crisis, fueron capitalizados políticamente por la oposición de izquierda, que supo a su vez canalizar el descontento social.

En el trasfondo del saldo negativo de las denominadas reformas económicas de segunda generación está la paradójica cohabitación entre democracia y desigualdades sociales persistentes. Si por una parte el liberalismo social con políticas sociales compensatorias y mantenimiento del gasto público social, consiguió reducir los niveles de pobreza medida por el método de la línea de ingresos pasaba de $41 \%$ de las personas en 1990 a 33\% de las personas en 1999(CEPAL), esa tendencia comenzaba a revertirse a partir de la crisis de 1999. Otros indicadores señalaban tendencias opuestas en la reproducción de las desigualdades sociales y cambios regresivos de la estructura social. El sector informal entre 1990 y 1997 creció ded 41 a $47 \%$ de la PEA (CEPAL), y el desempleo, también volvia a incrementarse. Pero el dato más significativo de la persistencia de las desigualdades sociales fueron los indicadores de distribución del ingreso, a partir del Indice de gini ,que mostraba la tendencia a reproducir e incrementar una distribución regresiva, la más alta de América Latina y de las más altas del mundo.

En 1990 el índice de Gini se situaba en 0,528, mientras que en 1999 se elevaba a 0,552 (CEPAL). Esto se expresaba que para 1999 mientras el $40 \%$ de los estratos de la población de menores ingresos recibía el 10,3\% del total de ingresos generados en 1999, el 10\% de estrato poblacional de más altos ingresos se apropiaba del $47,1 \%$ de lo producido ese año.

El agotamiento de las reformas liberalizantes, abrieron un nuevo escenario político de cara a las elecciones de 2002, en el cuál se conjugará la división del centro y de la alianza con los sectores conservadores. El espacio vacío será ocupado por una alianza política inédita, de un partido de izquierda con sectores de centro y 
una parte del empresariado en busca de un nuevo pacto desarrollista popular, dejando planteados varios desafíos para la democracia contemporánea.

Estos cambios en las alianzas políticas partidarias, se expresaron en el período a través de varios realineamientos políticos electorales.

Los cambios políticos más notorios se dieron en las elecciones presidenciales (ver cuadro 1). El primer realineamiento relevante fueron las elecciones de 1989, en las cuáles se presentaron dos polos opuestos. De un lado el ensayo de renovación populista de la derecha conservadora trás el liderazgo de Collor de Mello que aglutinó al $30,5 \%$ de los votantes. En el otro extremo, la izquierda, que disputó con dos candidaturas muy parejas, la de Brizola, expresión de la herencia trabalhista y Lula que provenía de la nueva izquierda de origen sindical la cuál se proyectó por primera vez como una alternativa política nacional. Además, en la coyuntura se produce una división del centro que tiene como resultado la emergencia del Partido de la Social Democracia Brasileña (PSDB) de Fernando Henrique que obtuvo $11,5 \%$ de las adhesiones.

Ante el fracaso del ensayo neopopulista los escenarios electorales de 1994 y 1998 tuvieron por una parte la mayoría absoluta de los votos aglutinados tras la candidatura de Fernando Henrique Cardoso, con una alianza estable entre el centro y los partidos de derecha conservadores. Por otro lado, la izquierda se fue coaligó desde la oposición, entre las dos grandes fuerzas PT y PDT. Asimismo, se produjo la emergencia de otra candidatura desde la izquierda, el PPS (antiguo PCB), que procuró un nuevo espacio de centro izquierda, y obtuvo el $11 \%$ de los votos.

Paralas elecciones de2002, se constatóunnuevorealineamiento político. De un lado se agotó la alianza entre los sectores de centro y partidos conservadores, con una candidatura de José Serra con poco carisma y bajo desempeño en la opinión pública que alcanzó el $23,2 \%$ de los votos. Esta candidatura recogío básicamente los votos del PSDB, más algún segmento más de centro. 
Cuadro 1 - Votación de los partidos en elecciones mayoritarias a cargos ejecutivos en Brasil (\% votos válidos por legenda partidaria, 1989-2002)

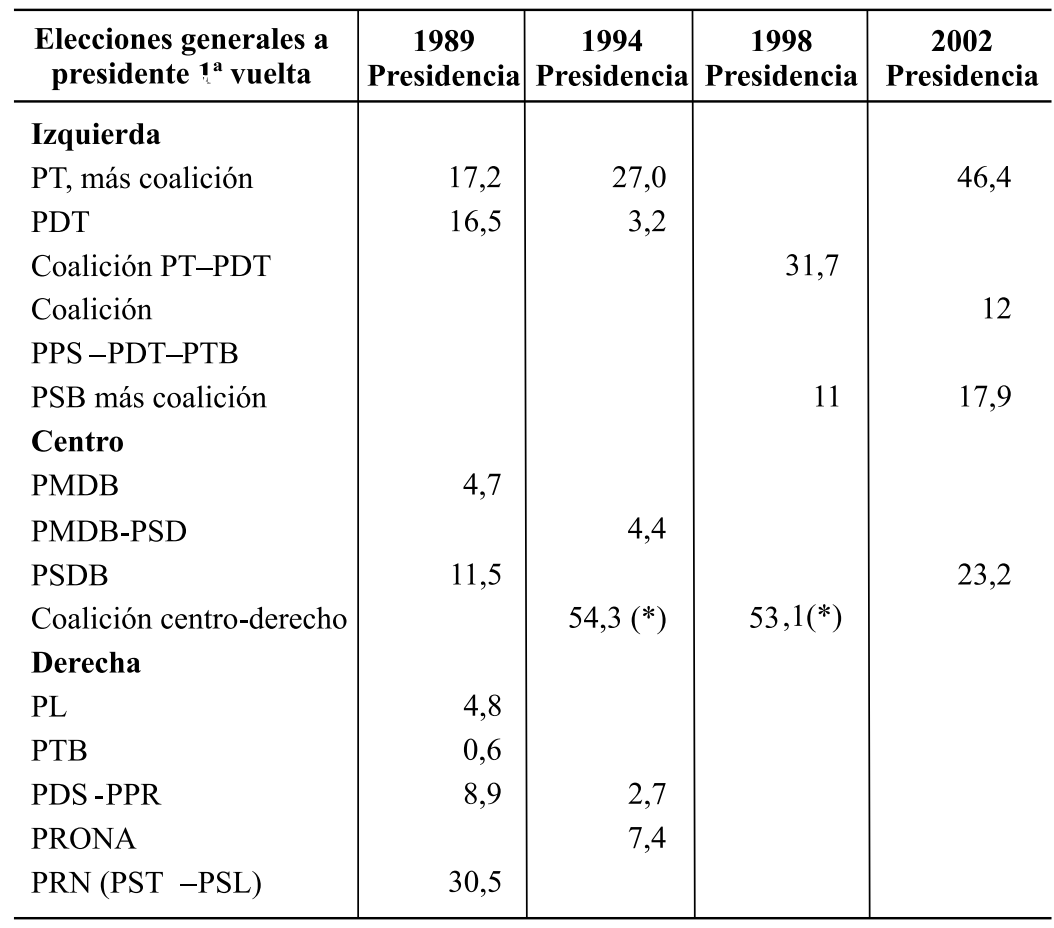

Fuente: TSE

(*) suma los votos coalición electoral del PFL y PTB en 1994 más los de PMDB, PPB en 1998.

Nota: Se excluyen los partidos que recibieron menos del $2 \%$ de los votos.

Por otra parte, la candidatura triunfante de Lula, obtendrá el $46,4 \%$ de los votantes en la primera vuelta. Esta candidatura presidencial expresará una coalición política inédita. En el plano formal electoral básicamente entre el PT y el Partido Liberal, un sector minotario de derecha empresarial, los cuáles ambos partidos sumados constituyeron el $22,7 \%$. Además, esta coalición política, expresaba una alianza entre la izquierda y un sector del centro, en el plano partidario, programático y social. Esta alianza con el centro y un sector conservador permitió superar el veto de los sectores 
conservadores, y un incremento sustancial del caudal electoral para ganar las elecciones.

Aparecieron también dos candidaturas desde la izquierda. De un lado, una alianza de todo el legado de izquierda histórica. El trabalhismo en sus dos vertientes (PDT de izquierda y populista conservadora, el PTB), sumado a la reconversión del antiguo Partido Comunista Brasileño en Partido Popular Socialista, obteniendo 12\% de los votos. La candidatura presidencial e Ciro Gomes recibió casi el mismo caudal electoral que los tres partidos miembros. De otro lado, aparece la candidatura de Anthony Garotinho, ex lider del PDT de Rio de Janeiro, de fuerte impronta carismática populista, que va a utilizar la legenda del PSB, para presentar una altenativa electoral que obtuvo el $17,9 \%$ de los votos.

Los realineamientos electorales entre los diversos sectores políticos ideológicos del sistema político brasileño, se expresaron cabalmente en la representación parlamentaria de los partidos (ver Cuadro 2).

Considerandoen conjunto todo elperíododeredemocratización se pudo observar que pese a la aparente fragilidad partidaria, los partidos y sus coaliciones obedecieron a reglas y espacios de acción bastante estables en el eje de izquierda-derecha. ${ }^{11}$ En síntesis se puede afirmar que el sistema multipartidista pre-64 se extinguió; y renglón seguido se reinstaló otro sistema multipartidista pos- 82 con nuevos actores políticos organizado en campos ideológicos claramente diferenciados.

Luego del realineamiento de la Constituyente de 1988 que marcó de algún modo el fin de la transición democrática resultado expresado en las elecciones de 1989, el mapa partidario a nivel electoral y parlamentario se mantuvieron los grandes bloques políticos-ideológicos (Rodrigues, 1995, p. 88). La restauración del multipartidismo fue acompañada del vaciamiento de las dos grandes fuerzas políticas creadas por el régimen autoritario (PMDB y el PDS) que se habían estructurado en función de la defensa y oposición al régimen. 
Cuadro 2 - Porcentaje de bancas obtenidos por los Partidos en la Cámara de Diputados en Brasil (1982-2002)

\begin{tabular}{l|r|r|r|r|r|r}
\hline & $\mathbf{1 9 8 2}$ & $\mathbf{1 9 8 6}$ & $\mathbf{1 9 9 0}$ & $\mathbf{1 9 9 4}$ & $\mathbf{1 9 9 8}$ & $\mathbf{2 0 0 2}$ \\
\hline Izquierda & $\mathbf{6 , 5}$ & $\mathbf{8 , 2}$ & $\mathbf{1 9 , 3}$ & $\mathbf{2 1}$ & $\mathbf{2 1 , 3}$ & $\mathbf{3 1 , 3}$ \\
PT & 1,7 & 3,3 & 7 & 9,6 & 11,3 & 17,7 \\
PDT & 4,8 & 4,9 & 9,1 & 6,6 & 4,9 & 4,1 \\
PSB & & & 2,2 & 2,9 & 3,7 & 4,3 \\
PC do B & & & 1 & 1,9 & 1,4 & 2,3 \\
PPS & & & & & & 2,9 \\
Centro & $\mathbf{4 1 , 8}$ & $\mathbf{5 3 , 4}$ & $\mathbf{2 9 , 1}$ & $\mathbf{3 3 , 0}$ & $\mathbf{3 5 , 5}$ & $\mathbf{2 8 , 2}$ \\
PMDB & 41,8 & 53,4 & 21,5 & 20,9 & 16,2 & 14,4 \\
PSDB & & & 7,6 & 12,1 & 19,3 & 13,8 \\
Derecha & $\mathbf{5 1 , 8}$ & $\mathbf{3 6 , 7}$ & $\mathbf{4 9 , 2}$ & $\mathbf{3 5 , 9}$ & $\mathbf{4 0 , 5}$ & $\mathbf{3 7 , 4}$ \\
PDS-PDC(*)-PPR-PPB & 49,1 & 7,8 & 12,7 & 10,1 & 11,7 & 9,6 \\
PFL & & 24,2 & 16,5 & 17,3 & 20,5 & 16,4 \\
PRN & & & 8 & & & \\
PTB & 2,7 & 3,5 & 7,6 & 6 & 6 & 5,1 \\
PL & & 1,2 & 3,2 & 2,5 & 2,3 & 5,1 \\
PSC & & & 1,2 & & & \\
PRONA & & & & & & 1,2 \\
\hline Total de bancas & $100 \%$ & $100 \%$ & $100 \%$ & $100 \%$ & $100 \%$ & $100 \%$ \\
& $\mathbf{( 4 7 9 )}$ & $\mathbf{( 4 8 7 )}$ & $\mathbf{( 5 0 3 )}$ & $\mathbf{( 5 1 3 )}$ & $\mathbf{( 5 1 3 )}$ & $\mathbf{( 5 1 3 )}$ \\
\hline
\end{tabular}

Fuente: Elaborado en base a TSE, Nicolau (1998).

Observación: se consideran aquellos partidos con más del 1\% de bancas.

(*) El PDS se funde con el PDC en 1993.

El centro se desinfló un poco en su significación política aunque continuó siendo el que aglutinó los partidos con mayor fuerza parlamentaria-electoral. La pérdida de representación política del PMDB (de 41,8\% en 1982 a 14,4\% en 2002 de las bancas a diputados) fue ocupada parcialmente por el PSDB (del 7,6\% de bancas en 1990 a 13,8\% en 2002).

En la derecha el vaciamiento de cuadros políticos antes agrupados en el PDS luego desplazados en el Partido Popular 
Brasileño (de 49,1\% de las bancas en 1982 a 9,6\% en 2002), fue sustituido por la conformación de un núcleo representado por el Partido del Frente Liberal que obtuvo al $16,4 \%$ de las bancas en 2002, y la dispersión de varias pequeñas fuerzas.

La organización de los partidos a nivel nacional durante todo el período se articuló también de acuerdo a las posiciones que alcanzaron en la disputa electoral por cargos gubernamentales para el control de las burocracias públicas. La actividad de gobierno continuó siendo un elemento nucleador y de fortalecimiento de las alianzas partidarias y de los partidos. La formación de gobiernos de coalición gubernamental se realizaron con la misma la lógica partidaria que operó en el nivel parlamentario y constituyó un elemento de cohesión en la actividad partidaria (Meneguello, 1998, p.52). En este plano lo más notorio fue la continuidad de la alianza entre el centro y la derecha en el período pos-1994.

Por último en el campo de la izquierda se produjeron tres tipos de tendencias evolutivas. Un proceso de crecimiento rápido con una notoria presencia en las elecciones presidenciales (con más del $30 \%$ de votantes) y una expansión relativa en las parlamentarias (de un 6,5\% de las bancas en 1982 a 31,3\% en 2002). Este campo ideológico tuvo cambios importantes en sus agentes políticos, en 1982, la hegemonía electoral estaba compartida entre el PDT y PT (con un predominio del primero), hasta las elecciones de 1998 donde la relación se invirtió y se percibió la ocupación progresiva del PT en tanto el principal partido de la izquierda. El PT pasó de 1,7\% de las bancas parlamentarias en 1982 al 17,7\% en 2002, mientras el PDT quedó restringido a una representación parlamentaria de 4,1\%.

Además se observó un crecimiento de la fuerza electoral de pequeños partidos comunistas y socialistas.

De un lado, la emergencia del Partido Socialista Brasileño (que pasa de 2,2\% de las bancas en 1990 al 4,3\% en 2002). El PSB compartió con el PDT la característica de ser un partido de izquierda continuador de tradiciones políticas pre-64 y que surgió en 1985 con el objetivo de refundar el proyecto de izquierda socialista democrática 
del PSB en 1947. La refundación de este partido pretendió ocupar un espacio propio de socialismo democrático, diferenciado de una parte de los clásicos partidos comunistas y del PT, y por otro, de las tradiciones de izquierda trabalhista. El énfasis específico de la propuesta partidaria se centró en la reivindicación simultánea de las banderas clásicas del socialismo, como ser la lucha contra la desigualdad social y la necesidad de intervención del Estado en la economía para corregir los efectos disfuncionales del mercado. Simultáneamente postuló la confluencia necesaria con la vertiente liberal, en especial en lo que respecta a la valorización del régimen democrático, así como la vigencia de los derechos ciudadanos y las garantías básicas del estado de derecho.

De otro lado, también aparecen pequeñas fuerzas desprendimientos del antiguo partido comunista brasileño, como el Partido Comunista del Brasil y el Partido Popular Socialista, que consiguieron hacia las elecciones de 2002 una bancada parlamentaria de 2,3\% y $2,9 \%$ respectivamente.

Es importante recordar que estos realimientos fueron lentos en el tiempo debido a los efectos condicionantes del sistema electoral, en especial la desproporcionalidad de los distritos mayores, así como entre partidos grandes y pequeños. Esto significó que los partidos de izquierda que tenían sus bases electorales más fuertes en distritos grandes, tuvieran una representacion parlamentaria menor a los votos obtenidos, e inversamente en el campo de los partidos conservadores obtuvieron sistemáticamente mayor cantidad de bancas, fundamentalmente por su desempeño en los distritos electorales más pequeños donde se concentraban sus bases clientelares. A medida que los partidos aumentaban el volumen del electorado y se extendían en toda la Federación comienzaban a tener una representación parlamentaria bastante similar, no obstante persistió la subrepresentación de los partidos más pequeños.

Los cambios en las fuerzas políticas partidarias se produjeron no sólo debido a los cambios estructurales en las relaciones entre 
Estado y Sociedad, o de las dinámicas de la instituciones políticas, sino también por un proceso de largo plazo de reconversión ideológica y adaptación política de los sujetos políticos en su integración al juego político democrático.

La reconversión de los actores políticos se realizó desde los dos extremos del sistema político.

a) La reconversión de los partidos conservadores se produjo por medio de la integración al juego democrático en un doble proceso histórico. Por una parte, de adaptación a las nuevas condicionantes externas e internas. De otra parte, la reconversión ideológica y de las bases sociales para reproducir sus fuerzas dentro del sistema político. Este proceso se expresó en tres planos diversos.

En el ámbito de la política, durante el proceso de institucionalización de la nueva fase democrática, los partidos conservadores tuvieron un "notable exito" en el "mantenimiento del poder político" (Mainwaring, Meneguello, Powers, 2001, p. 12). Los partidos de derecha reprodujeron un fuerte peso en el control de los resortes de poder estatal desde el ámbito nacional hasta los espacios más capilares de los municipios locales. A su vez la presencia política de los mismos se sostuvo en un buen desempeño político electoral en la transición del autoritarismo a la democracia.

Los partidos de derecha mantuvieron una influencia importante en el nivel nacional, tanto por haber participado sistemáticamente en las coaliciones de gobiernos, como por haber obtenido una representación parlamentaria amplia, controlando promedialmente el $41,9 \%$ de las bancas en la cámara de diputados y el $42,5 \%$ de las bancas del senado entre 1982 y 2002.

Asimismo, tuvieron un control relevante en los ámbitos de gobiernos regionales y locales. En el período de 1982 a 2002 obtuvieron el $31,4 \%$ de los gobernadores y más del 51,4\% de los intendentes electos. 
La influencia del bloque conservador fue más amplia que la representación de los partidos de derecha. Los partidos conservadores no tenían sectores de centro e izquierda, mientras que partidos de centro tienen políticos y alas conservadoras, por tanto los políticos conservadores eran más que los partidos (Mainwaring, Meneguello, Powers, 2001, p. 53).

La presencia de los partidos de derecha reprodujeron varios de los rasgos históricos de la matriz política conservadora. En el plano de las propuestas programáticas se manifestaron propensos al presidencialismo, reforzando el personalismo en la representación política, y la preferencia a ocupar espacios en estructuras políticas estaduales y locales. Como contracara, en el plano organizativo expresaron actitudes antipartidarias, baja disciplina partidaria, bajos niveles de fidelidad partidaria y dependencia de prácticas clientelísticas (Mainwaring; Meneguello; Powers, 2001, p. 91).

Otro plano de transformación fueron la reconversión de las bases sociales de los partidos conservadores. Por un lado, en la representación política de las elites expresaron el peso histórico de intereses agrarios y conservadores en el Congreso.

En un estudio sobre las bancadas parlamentarias Cámara Federal de 1998 (Rodrigues 2001) se mostró diferencias en los perfiles y bases sociales entre las diversas familias políticas ideológicas. Por ejemplo, en los perfiles ocupacionales los tramos de ingresos patrimonial más altos predominaban en parlamentarios de derecha, en contraposición a los más bajos en los de partidos de izquierda.

En la caracterización social de los grandes partidos las bases sociales de las elites se expresaban claramente. Los dos partidos de derecha más grandes tenían una composición social similar. El Partido Popular Brasileño se caracterizaba por un perfil social predominante de los sectores empresarios urbanos y rurales $(68 \%)$, acompañado de un sector de profesionales liberales tradicionales (Rodrigues, 2001, p. 29). Por su parte, el Partido del Frente Liberal 
también contaba con un perfil social predominante de los sectores empresarios urbanos y rurales (61\%), sumado a un sector vinculado al Estado de la alta burocracia federal o estadual, y una proporción minoritaria de profesionales liberales (Rodrigues 2001, p. 30). ${ }^{12}$

Por otro lado, los partidos conservadores lograron un buen desempeño electoral a través de la reproducción de bases sociales específicas. Las bases de los partidos de derecha se apoyaron en el reclutamiento en las regiones menos desarrolladas - principalmente del nordeste -, en el control de los pequeños municipios y la utilización de los mecanismos clientelares tradicionales. Asimismo, su electorado se caracterizó por pertenecer a los sectores sociales más pobres, en los tramos tramos de ingreso económico más bajos, con niveles de instrucción menores, y de edades más avanzadas (Mainwaring; Meneguello; Powers, 2001, p.13). Más allá de estos elementos comunes, también se identificaron dos patrones de reclutamiento electoral distintos entre los partidos conservadores, el mayoritario o tradicional que respondió a la caracterización previa, y otro, más moderno que representaba a electores de mejores ingresos, más altos niveles educativos y residentes en regiones más desarrolladas y municipios grandes (ejemplo del electorado del Partido Liberal).

La reconversión de los partidos conservadores se expresó a su vez en la reorientación discursiva e ideológica, en la economía con posturas favorables a las políticas de liberalización económica, en la política con actitudes y comportamientos de mayor apoyo al régimen democrático, mientras que se mostraron más conservadores en cuestiones de seguridad pública y moral familiar (Mainwaring; Meneguello; Powers, 2001, p.13).

En relación con el apoyo de las reformas económicas liberalizantes expresaron posiciones pro-mercado, más abiertos al capital extranjero, y favorables a la reformas económicas neoliberales del Estado, como ser la reducción del gasto público y la privatización de empresas públicas. En este plano existieron "diferencias significativas" entre los partidos conservadores. Por 
un lado aquellos partidos (PRN, PDS-PPB y PL) que expresaron un discurso "conservador bien articulado y coherente", desde las regiones económicas desarrolladas del país, principales impulsores del giro y defensa ideológica del "neoliberalismo" (en sus dos versiones: populista/liberal conservadora). Por outro lado, aquellos sectores menos ideológicos y más clientelístas o personalistas, lo que facilitó un mejor desempeño entre electores menos instruídos y residentes de pequeños municipios.

Este liberalismo económico fue acompañado de posiciones conservadores en las "cuestiones sociales". El énfasis del crecimiento económico sobre las cuestiones distributivas, la oposición a la reforma agraria, el rechazo a incrementar derechos y protecciones sociales que pudieran limitar el crecimiento económico, y con posiciones conservadoras en temáticas de moralidad familiar - contra legalización aborto e igualdad derechos a homosexuales (Mainwaring; Meneguello; Powers, 2001, p. 36-38).

El otro giro ideológico relevante fue la tendencia de los partidos conservadores a una mayor aceptación del régimen democrático que en otros períodos históricos previos. Los partidos de derecha previos a 1984 habían contribuído muy poco al mantenimiento de la democracia, con muchos comportamientos antidemocráticos y con una percepción de la democracia como "amenaza" a sus intereses. A partir de 1985 tuvieron una reorientación discursiva de aceptación progresiva del régimen democrático.

Varios factores pueden haber contribuído a dicha metamorfosis del comportamiento democrático. La "amenaza de cambio social radical" fue muy baja en el período de redemocratización. El "establishment conservador moderno" tuvo una mayor disposición a la aceptación de la democracia, en tanto la "derecha autoritaria tradicional" estaba en retroceso. Los "conservadores reconocieron que el régimen militar no fue una solución" y están más renuentes a una interveción militar. A ello debe agregarse cambios en el contexto internacional más favorables "de apoyo a la democracia", 
de manera que el "costo de oponerse frontalemente a la democracia ha aumentado" (Mainwaring; Meneguello; Powers, 2001, p. 104).

b) La reconversión de las izquierdas. La integración de las izquierdas en la nueva fase democrática, se dió a traves de un doble recorrido histórico, de un lado, la adaptación de las izquierdas a un contexto externo nacional e internacional que plantearon nuevos desafíos y, por otro lado, los procesos internos de reconversión ideológica de las identidades de las izquierdas.

Las izquierdas llevaron pues un tipo de integración parcial al juego democrático. que se expresó en tres planos (Serna, 2004, Cap.1).

En el ámbito político institucional se produjo una creciente participación de las izquierdas en la competencia electoral e institucional por cuotas de poder en el sistema político. Sin embargo, estos avances en la representación política fueron parciales, constituyendo minorías desafiantes contra mayorías políticas conservadoras en un clima de época inundado por el neoliberalismo. La integración política parcial se constató también en las carreras políticas de los líderes de izquierda a través de una preminencia de legado histórico del papel opositor y de resistencia desde dentro y fuera de los ámbitos políticos institucionales. Las trayectorias de los dirigentes mostraron pautas de carreras parlamentarias y partidarias claramente establecidas. A su vez, la experiencia restringida en la actividad gubernativa fue un indicador del peso de la tradición de oposición política y resistencia extraparlamentaria de las izquierdas (Serna, 2004, Cap. 3).

A pesar de la creciente visibilidad de los candidatos y partidos de izquierda en las elecciones presidenciales nacionales, el acceso al control de elencos de gobierno fue limitado. La baja participación promedio de las izquierdas en el acceso al gobierno de los estados durante el período 1982-2002 fue muy clara. Los tres partidos más visibles (PDT, PSB y PT) sumados eligieron tan sólo al 15,9\% de todos los gobernadores de la Federación. ${ }^{13}$ 
La dificultad para ocupar cargos ejecutivos se hizo más notoria cuando se analiza el desempeño electoral en los municipios para el período 1982-2002. Todos los partidos de izquierda sumados (PDT, PSB, PT más los pequeños partidos) apenas alcanzaron a controlar el 9,3\% de los intendentes electos, y el PT exclusivamente sólo el $1,3 \%$ de los municipios.

En un segundo plano, en la sociedad, las izquierdas emergieron como agentes políticos de expresión e intermediación de intereses sobre nuevas y viejas cuestiones sociales agravadas por la implementación de las reformas económicas neoliberales. Se puede llamar a este plano de actuación de las izquierdas como el papel de "tribuno de la plebe", expresión de los intereses de los sectores sociales subalternos más vulnerables al interior del sistema político democrático. En este sentido, se encontraron evidencias que en las bases sociales de los partidos de izquierda, redes asociativas relacionadas con viejas y nuevas cuestiones sociales (asociaciones gremiales del mundo del trabajo trabajo, organizaciones del campo de la educación y la cultura, derechos humanos y de minorías, etc.), así como por los vacíos y déficits sociales dejados por la crisis del Estado de Bienestar (Serna, 2004, cap. 3).

A su vez, hay que considerar que el campo de la izquierda estuvo signado por una expansión territorial desigual y heterogénea de sus bases sociales electorales.

El PDT mostró sus mejores desempeños electorales en las regiones de mayor desarrollo del Sur y Sureste, y también por medio de alianzas partidarias variables en la región Norte y Noreste. Por outro lado, el electorado del PSB tuvo una extensión territorial desproporcional y con fuertes anclajes regionales. Una parte de sus bastiones electorales y sociales se ubicaron en la región Noreste tradicional, y en el otro extremo en la región sureste, en las áreas más modernas en las principales ciudades y centros urbanos que han sido los bastiones electorales "tradicionales" de la izquierda.

El PT surgió como partido nuevo en las regiones más modernas e industrializadas con bases electorales en la región Sureste y Sur. A 
partir de las elecciones de 1989 que se transformó en fuerza nacional, fue extendiendo penetración electoral progresivamente hacia en el resto de las regiones, con especial impacto en estados que pasaron por procesos de modernización acelerada y autoritaria.

Por último, en el plano discursivo de las izquierdas se constató una reconversión ideológica mediante la incorporación de la cuestión democrática y la valorización de las instituciones políticas que contribuyó a la legitimación parcial de la democracia. El proceso de incorporación de la cuestión de la democracia en el discurso e identidad de las izquierdas se plasmó en cuatro modos de reconversión ideológica de la izquierda en democracia: el camino republicano, la vía socialdemócrata, la reinvención nacional de socialismo y las corrientes de democracia radical (Serna, 2004, Caps. 4 y 5$)$.

El camino republicano seguido fundamentalmente por el centro izquierda se postuló como una apuesta por una forma de reapropiación de la democracia enfatizando la ética republicana de valorización del funcionamiento transparente de las instituciones políticas y de la recuperación de la autonomía política como el espacio de los intereses públicos.

La vía socialdemócrata fue ensayada por las corrientes de izquierda más moderadas que conjugaron la recuperación de tradiciones políticas nacionales y de reforma social de izquierda alternativas al neoliberalismo, pero diferenciadas de la izquierda socialista clásica. Asimismo, aparecieron como una propuesta aggiornada de la izquierda mediante la importación doctrinaria de corrientes de socialismo democrático europeas (de pos-segunda guerra mundial).

La reinvención nacional de las tradiciones socialistas tuvo a su interior variantes, no obstante, el eje se basó en la intención de compatibilización de los principios de la democracia representativa liberal, amoldándolos en las experiencias socialistas nacionales. 
Esto supuso una reconversión ideológica mediante una doble reinterpretación: de la confluencia entre las reivindicaciones democráticas y las metas socialistas, y la superposición con la recuperación de las raíces nacionales en la implantación de los partidos socialistas.

El cuarto camino ensayado por las izquierdas fue la radicalización de la democracia, que consistió en la profundización y extensión de los principios democráticos para construir un proyecto democrático más desarrollado e integral, con nuevos proyectos de democracia participativa desde la base.

La reconversión política interna de la cuestión democrática en la izquierda se complementó con una reorientación de la legitimación externa de la democracia, en un doble sentido. Las izquierdas se integraron por medio de una valorización general positiva de la democracia como sistema político preferible frente a otros, y al mismo tiempo, reclamando una actitud crítica de necesidad de superar las insuficiencias de las democracias existentes.

Esta reorientación ideológica se produjo a su vez con respecto a la economía, con una "moderación programática" en cuanto a la "necesidad" de cambios "estructurales" del sistema capitalista. Esta moderación se dió en un clima signado por una parte de cambios de contextos a nivel internacional de reestructuración de los bloques económicos dominantes, la crisis de las economías de "socialismo real", la hegemonía del pensamiento neoconservador y neoliberal, la pérdida de influencia de las teorías marxistas -revolucionarias y ortodoxas- para dar cuenta de los cambios sociales y políticos contemporáneos. Por otra parte, debido a las transformaciones de la estructura social que desestructuraron las bases tradicionales del mundo del trabajo unido a una influencia mayor del capital transnacional y la globalización de la vida social. Sin embargo, esta "moderación" de las críticas a los efectos económicos del sistema capitalista no se tradujo en la elaboración de modelos o políticas económicas alternativos claros y consistentes. 
No menores fueron las dificultades en la esfera social. Por una parte la aceptación del régimen capitalista y la Democracia se ha realizado junto a la convivencia con niveles crecientes y magnitudes considerables de sectores sociales afectados por situaciones de exclusión social, y frente a un Estado Social "deshuesado" con baja capacidad de atender a los problemas de la vulnerabilidad y desintegración social.

\section{De cambios y permanencias}

El agotamiento del ciclo de reformas neoliberales y la carrera hacia el gobierno nacional de un partido de izquierda abrió oportunidades para el recambio de elencos políticos. Ello no supuso un cambio radical en las concepciones de gobierno, por el contrario continúa la persistencia de lo que podría denominarse la política económica del programa mínimo y la hegemonía del pensamiento económico convencional sobre el desarrollo. Uno de los aspectos que más llama la atención es la persistencia de enfoques de "cuño economicista" en la perspectiva del desarrollo, que se expresa de múltiples formas. La centralidad de la política económica en las decisiones de la agenda gubernamental, unida a la creencia que la restricción de recursos económicos y la austeridad fiscal en su uso debe orientar las políticas públicas. La creencia que el gradualismo y la ortodoxia en las políticas económicas asegura la estabilidad económica y la atracción de capital extranjero. Asimismo, se minimizan los condicionantes y cambios de contexto externo en los logros de las políticas de corto plazo. La autonomía de la política económica y la minimización de la intervención de la política. El gasto social debe tener como prioridad una reasignación más eficiente del mismo hacia los sectores más carenciados para compensar los efectos disfuncionales de la propia economía.

El corolario de la gobernabilidad económica, es la ausencia de articulación entre las políticas económicas y sociales, o mejor dicho, la prioridad del desarrollo económico y la concepción del desarrollo social exclusivamente como políticas sociales de corte "bomberil" 
para palear los efectos disfuncionales de la exclusión económica. La minimización de las desigualdades económicas y sociales, va de la mano con la reproducción de la "teoría del derrame" (originada en estudios de Kutznet), conocida popularmente como el discurso de primero crecer y luego distribuir, plantea un círculo virtuoso entre crecimiento y distribución de la riqueza, de discutible comprobación empírica. El crecimiento económico tendría efectos sociales positivos porque genera más empleos, mejora los ingresos salariales y la capacidad de consumo y bienestar de la población. Asimismo, la utilización del consumismo y el crédito como herramientas reproductoras del conformismo social.

A los imperativos de la gobernabilidad económica se sumaron los de la política. Desde el inicio el gobierno se enfrentó al desafío de administrar una coalición heterogénea e inestable en su composición. Se trata de una coalición inestable porque está compuesta por un partido orgánico y de masas, pero que sólo controla un quinto del parlamento, y por tanto que requiere de socios, y hasta ahora, los que tiene han sido pequeños partidos, o fracciones de partidos más grandes, así como un segmento nada despreciable del $20 \%$ de parlamentarios que no tienen ninguna adhesión partidaria (simplemente se alinean con el gobierno de turno para obtener mayores beneficios individuales). Desde el punto de vista ideológico, integra sectores políticos conservadores que más de una vez en la historia brasileña han sido actores de veto a iniciativa progresistas populares. ${ }^{14}$ En el plano social, expresa una alianza entre sectores de trabajadores organizados, estado y empresarios nacionales (más el apoyo tácito del establisment financiero internacional), confluencia de intereses que es posible en la medida que el desarrollo económico distribuya beneficios para todas las partes.

Los imperativos de la gobernabilidad política no sólo limitan el juego de los actores, también seducen en la búsqueda y mantenimiento del poder, en ese sentido, la última fase del mandato de Lula está cada vez más influenciada por el escenario electoral del 2006. 
Al momento de diagnosticar los rumbos de la experiencia del gobierno Lula queda un sabor agridulce. Decir, que es la mera continuidad de los gobiernos de F. H. Cardoso, sería falso. Cambiaron varios aspectos en la política brasileña. En primer lugar, la renovación de la clase política dando lugar a una participación en el poder político de elencos de los sectores sociales subalternos históricamente excluídos. Asimismo, se abrieron canales en la estructura del estado (fundamentalmente por medio de Consejos) para una participación más directa de los sectores de la sociedad civil organizada. Cambió también la base de gobierno, de una coalición liberal social conformada por un centro y una derecha orgánica, se sustituyó por una coalición más heterogénea, conformada por la izquierda organizada, con un sector del centro y una parte de los partidos conservadores. Cambió la base social de apoyo, de un reformismo neoliberal de Cardoso basado en un sector técnico modernizador apoyado en el capital multinacional y sectores oligárquicos tradicionales, hacia una coalición de trabajadores sindicalizados, con un sector de la burguesía nacional, la tolerancia del capital financiero y el apoyo pasivo de sectores conservadores y los sectores subalternos no organizados (que constituye una gran masa popular de ese Brasil excluído), alianza moderada por la figura carismática popular de Lula.

En cuanto a las políticas públicas, la política económica si bien no se alteró sustancialmente, se frenó el avance privatista del sector público y se reorientó la política exterior hacia la defensa de la soberanía nacional frente a los embates de la globalización, pero no en sentido tradicional de resistencia, sino de resignificación en el marco de los espacios multilaterales e interestatales. Tampoco se alteraron sustantivamente las políticas sociales y de redistribución del ingreso, aunque profundizaron su liberalismo social, y reorientó su filosofía reivindicando más una cultura de derechos, que un simple asistencialismo con fachada democrática.

¿Qué cosas no fueron modificadas? Al menos en el corto y medianoplazo, eldesarrollo periférico en cuestión, fundamentalmente debido a la persistencia de la vulnerabilidad externa - agravada 
por la volatilidad del capital financiero y el endeudamiento - y los imperativos del mercado internacional como condición estructural para el desarrollo nacional (a pesar de las potencialidades de la economía brasileña). A su vez, un aspecto más grave, la dificultad para transformar un patrón histórico de desarrollo social desigual, concentrador y excluyente (con las peores distribuciones de la riqueza de América Latina y del mundo). Un patrón de subdesarrollo o vulnerabilidad de la cuestión social que expresa dramáticamente las distintas caras de la exclusión social contemporánea, la del capitalismo avanzado con trabajadores flexibles y la amenaza de pasar a engrosar los supernumerarios sin empleo, la del sector informal urbana que tiene un desarrollo paralelo a la modernización (la razón dual de Francisco de Oliveira) pero sin obtener los frutos y derechos de la misma; y además la marginación histórica herencia de una sociedad semiesclavista, rural y parroquial. ${ }^{15}$

Tampoco se modificó el conservadurismo político que tiñó la política brasileña desde el origen de la nación. El personalismo, la apropiación patrimonialista del aparato estatal, la simbiosis entre espacios públicos y privados, el clientelismo político y la corrupción como su manifestación más visible, no se han modificado en el corto plazo.

\section{Notas}

1 Las principales regiones de Brasil (Rio de Janeiro, Minas Gerais, San Pablo y Rio Grande del Sur) se conformaron en función del control de distintas fuentes de poder e intereses regionales, como ser la cercanía a las sedes administrativas de gobierno central, áreas productivas vinculadas al comercio exterior, el peso económico y demográfico de algunos estados, el desarrollo militar, que les dieron diversas cuotas de poder político en la dinámica y negociación con el gobierno central (Schwartzman, 1975, cap. II).

2 El texto más referido desde esta postura es el de Bolívar Lamounier y Raquel Meneguello (1986) que no dudan en catalogar el sistema como un caso de "subdesarrollo" partidario. Dentro de esta línea 
interpretativa se destaca más recientemente el trabajo comparativo de Scott Mainwaring y Timothy Scully (1994, p. 43-79) que ubican a Brasil entre los sistemas partidarios menos institucionalizados de América Latina.

3 El proceso de institucionalización progresiva de un sistema de partidos multipartidario hasta 1964 se manifestó en cuatro dimensiones: a) la incorporación de las diferencias regionales y de desarrollo socioeconómico como clivajes estructurantes en las disputas electorales; b) la sedimentación y estabilización de los patrones de competencia política por los cargos públicos; c) la articulación compleja entre las diversas categorías de conflictos por medio de una pluralidad de actores políticos; d) el enraizamento social de los partidos que se transformaron en conductos de expresión e identificación de preferencias electorales.

4 El término populista ha recibido múltiples acepciones en la extensa literatura académica existente, no obstante en América Latina existe cierto consenso que el fenómeno tuvo un período sociohistórico de auge en la década del 50', y los ejemplos más paradigmáticos fueron el varguismo y el peronismo.

5 El régimen autoritario iniciado en 1964, reinstaló un Parlamento en 1966 con una competencia y representación política restringida a dos partidos.

6 La oposición obtuvo en estas elecciones diez de los 23 gobernadores estaduales y la pérdida de la mayoría absoluta del oficialismo en la Cámara de Diputados.

7 El PTB contaba en 1980 con 23 diputados y un senador que con la escisión el PDT va a quedar con diez diputados, sin senador y luego va a lograr nuevas incorporaciones sobretodo del MDB (Sento-Sé, 1999, p. 98).

8 Para comprender la complejidad de dimensiones presente en la crisis se puede consultar Camargo (1989).

9 Este proceso de democratización no estuvo ausente de resistencias y tensiones. Por ejemplo, en la asamblea constituyente de 1988 se planteó un proyecto de mayor parlamentarización del sistema, con creación de un régimen semipresidencial que no tuvo aprobación. 
10 En este sentido, se legalizaron de los derechos sindicales de los trabajadores, se aseguró la libertad de organización en asociaciones nacionales y la eliminación de los controles directos del Ministerio de Trabajo.

11 Este aspecto ha sido un punto recurrente de polémica en la academia brasileña. Con un objetivo de captar el funcionamiento y cambios de largo plazo es importante el aporte realizado por Limongi Fernando y Cheibub Figueiredo Argelina acerca del comportamiento de los diputados federales de acuerdo a su afiliación partidaria donde comprobaron la existencia de patrones ideológicos clásicos de izquierda y derecha. (Limongi; Cheibub, 1995, p. 516).

12 Es interesante anotar, las distancias relativas y convergencia en la composición social con los partidos de centro. Por un lado, Partido de la Social Democracia Brasileña fue caracterizado como la expresión de la "burguesía intelectual"o "alta intelligentsia" (Rodrigues 2001, p. 26), asociación entre un sector minoritario empresarial urbano y una fracción intelectual de profesionales liberales, altos cargos de gobierno y profesores, --presencia de formación en ciencias humanas-. Por otra parte, existió una ausencia de empresarios rurales y clases populares. El otro partido de centro, el Partido del Movimiento Democrático Brasileño era más heterogéneo, una fracción empresarial predominante pero no mayoritaria, presencia de profesionales liberales y profesores era bastante elevada (20\%) - -más que en los partidos de derecha, aunque menos que en los de izquierda --, de ingresos patrimoniales medios y con ausencia de sectores populares (Rodrigues, 2001, p. 30).

13 Tendencia que parece revertirse parcialmente considerando exclusivamente las elecciones de 2002 que entre los 3 partidos eligen $29,6 \%$ de los gobernadores. No obstante, también debe recordarse que fue en esta elección donde los tres partidos presentaron candidaturas y alianzas presidenciales diferentes.

14 Casos más recientes, la aparición del presidente de la Cámara de Diputados Severino Cavalcanti, o las denuncias de corrupción iniciadas por Roberto Jefferson, líder de un partido que participó de todos los gobiernos nacionales desde la época de los militares al presente.

15 Dos ejemplos bastantes visibles de los obstáculos, han sido hasta ahora los pocos avances en la reforma agraria y las reacciones a la 
fiscalización de trabajo en condiciones de esclavitud, que se expresó en forma extrema en la muerte de tres fiscales de trabajo en enero de 2004.

\title{
Reconversion and political conservativeness in Brazil: the boundaries of change
}

\begin{abstract}
Drawing on comparative historical perspective, the article examines the recent political changes in the party system and Brazilian democracy. On the one hand, the paper explains historical restrictions on the democratization processes. On the other hand, it highlights the inheritance of conservative sociopolitics matrix on the dynamics of electoral changes. The first section analyzes the conservative sociopolitics matrix's development and identifies democratization processes' weaknesses between 1945 and 1964. The second section focuses on political parties and democracy development during the last decades to identify the limits of the recent political changes.
\end{abstract}

Key-words: democracy, conservative ideology, political parties, political changes.

\section{Bibliografía}

ARTURI, Carlos. As eleições no processo de transição à democracia no Brasil. In: BAQUERO, Marcello (Org.) Transição, eleições, opinião pública. Porto Alegre: Ed.UFRGS, 1995.

BODEA, Miguel. Trabalhismo e populismo no Rio Grande do Sul. Porto Alegre: Ed. UFRGS, 1992.

CAMARGO, Aspásia. As dimensões da crise. In: CAMARGO, Aspásia; DINIZ, Eli (Org.). Continuidade e mudança no Brasil da Nova República. Rio de Janeiro: Ed. IUPERJ, Vértice, 1989.

CARVALHO, José Murilo De. A construção da ordem e Teatro de sombras. Rio de Janeiro: Ed. UFRJ, Relume Dumará, 1996.

. A formação das almas: o imaginário da República no Brasil. São Paulo: Companhia das Letras, 1990. 
DINIZ, Eli; BOSCHI, Renato. A consolidação democrática no Brasil, atores políticos, processos sociais e intermediação de intereses. In: DINIZ, Eli et al. Modernização e consolidação democrática no Brasil: dilemas da Nova República. São Paulo: Vértice, 1989.

DUARTE, Nestor. A ordem privada e a organização política nacional. São Paulo: Cia. Editora Nacional, 1966.

ESPING-ANDERSEN, Gosta. Después de la edad de oro: el futuro del Estado Benefactor en el nuevo orden mundial. Revista de IDES, Buenos Aires, n. 142, jul./set. 1996.

FAORO, Raymundo. Existe um pensamento político brasileiro. São Paulo: Atica, 1994.

. Os donos do poder. Porto Alegre: Globo, 1979. 2 v.

KECK, Margaret. PT a lógica da diferença. São Paulo: Ática, 1991.

KINZO, Maria d'Alva. Representação política e sistema eleitoral no Brasil. São Paulo: Ed. Símbolo, 1980.

LAMOUNIER, Bolívar; O 'Brasil autoritário' revisitado: o impacto das eleições sobre a abertura. In: STEPAN, Alfred (Org.). Democratizando o Brasil. Rio de Janeiro: Paz e Terra, 1988.

LAMOUNIER, Bolívar; MENEGUELlo, Raquel. Partidos políticos e consolidação democrática: o caso brasileiro. São Paulo: Ed.Brasiliense, 1986.

LAVAREDA, Antônio. A democracia nas urnas: o processo partidário eleitoral brasileiro. Rio de Janeiro: Rio Fundo, IUPERJ, 1991.

LIMA Jr., Olavo Brasil de. Os partidos políticos brasileiros: a experiência federal e regional, 1945-1964. Rio de Janeiro: Graal, 1983.

LEAL, Victor Nunes. Coronelismo, enxada e voto. São Paulo: Alfa-Omega, 1993.

LIMONGI, Fernando; FIGUEIREDO, Argelina Cheibub. Partidos políticos na Câmara dos Deputados, 1989-1994. DADOS Revista de Ciências Sociais, Rio de Janeiro, v. 38, n. 3, 1995.

MAINWARING, Scott. Políticos, partidos e sistemas eleitorais: o Brasil numa perspectiva comparativa. Revista Novos Estudos CEBRAP, São Paulo, n. 29, marzo, 1991. 
MAINWARING, Scott; SCULLY, Timothy. A institucionalização dos Sistemas Partidários na América Latina. DADOS Revista de Ciências Sociais, v. 37, n. 1, 1994.

MAINWARING, Scott, MENEGUELlO, Raquel; SCULLY, Timothy. Partidos conservadores no Brasil contemporâneo. Rio de Janeiro: Paz e Terra, 2000.

MALLO, Susana; SERNA, Miguel (Orgs.). Seducción y desilusión: la política latinoamericana contemporánea Montevideo: Ed. Banda Oriental, 2001.

MALlO, Susana; MOREIRA, Constanza (Orgs.). La larga espera: itinerarios de las izquierdas en Argentina, Brasil y Uruguay. Montevideo: Depto. de Sociología, CSIC, Universidad de la República, Editorial Banda Oriental, 2000.

MARENCO, André. Não se fazem oligarquias como antigamente: recrutamento parlamentar, experiência política e vínculos partidários entre deputados brasileiros (1946-1998). Tese (Doutorado em Ciência Política) - Universidade Federal do Rio Grande do Sul, Porto Alegre, 2000.

MENEGUELLO, Raquel. Partidos e governos no Brasil contemporâneo (1985-1995). Rio de Janeiro: Paz e Terra, 1998.

. PT: a formação de um partido 1979-1982. Rio de Janeiro: Paz e Terra, 1989.

MERCADANTE, Paulo. A consciência conservadora do Brasil. Rio de Janeiro: Saga, 1965.

MOISES, José Alvaro. Os brasileiros e a democracia: bases sócio-políticas da legitimidade democrática. São Paulo: Ática, 1995.

NICOLAU, Marconi Jairo. Dados eleitorais do Brasil (1982-1996). Rio de Janeiro: IUPERJ-UCAM, Revan, 1998.

O’DONNELL, Guillermo. Contrapuntos: ensayos escogidos sobre autoritarimo y democratización. Buenos Aires: Paidós, 1997.

PALERMO, Vicente (Comp.). Política brasileña contemporánea: de Collor a Luna en años de transformación. Buenos Aires: Instituto Torcuato di Tella, Ed. Siglo XXI, 2004.

RODRIGUES, Leôncio Martins. Direita, centro e esquerda: partidos, ideologia e composição social. Ponencia en el Seminario Partidos, Eleições e Repressentação política, en XXV Encontro Anual da ANPOCS, Caxambu, MG, 16-20 octubre 2001. 
RODRIGUES, Leôncio Martins. As eleições de 1994, uma apreciação geral. DADOS Revista de Ciências Sociais, v.38, n. 3, 1995.

SALLUM JUNIOR, Brasilio. Metamorfosis del Estado Brasileño a finales del Siglo XX. In: PALERMO, Vicente (Comp.). Política brasileña contemporánea. Buenos Aires: Instituto Torcuato di Tella, Ed. Siglo XXI, 2004.

SALLUM JUNIOR, Brasilio; GRAEFF, Eduardo; LIMA, Elizabeth Gomes de. Eleições presidenciais e crise do sistema partidario. Lua Nova Revista de cultura e política, São Paulo, mayo, 1990.

SANTOS, Wanderley Guilherme dos. Cidadania e justiça. Rio de Janeiro: Zahar, 1978.

SERNA, Miguel. Reconversão democrática das esquerdas no Cone Sul. San Pablo: EDUSC, 2004.

Los usos del análisis comparado: de la etiqueta metodológica a las comparaciones sustantivas. In: SERNA, Miguel; MALLO, Susana; PATERNAIN, Rafael (Orgs.). El fin de siglo y la política en Argentina y Uruguay. Montevideo: Ed. Alejandría, 1998.

SENTO-SÉ, João Trajano. Brizolismo. Rio de Janeiro: Ed. FGV, 1999.

SINGER, Andre. Esquerda e direita no eleitorado brasileiro. São Paulo: Ed. USP, 2000.

SCHWARTZMAN, Simon. Bases do autoritarismo brasileiro. Brasília: Universidade de Brasilia, 1982.

. São Paulo e o Estado Nacional. São Paulo: Difusão Européia do Livro, 1975.

SOUZA, Maria do Carmo Campello de. Estado e partidos políticos no Brasil 1930 a 1964. São Paulo: Ed. Alfa-Omega, 1976.

TRINDADE, Hélgio. La construcción del Estado nacional en Argentina y Brasil: 1810-1900. Revista Mexicana de Sociología, México, jan./ mar. 1986.

. Bases da democracia brasileira: lógica liberal e práxis autoritária 1822-1945. In: ROUQUIÉ, A.; LAMOUNIER, B.; SCHVARZER, J. Como renascem as democracias. São Paulo: Brasiliense, 1985. p. 46-72.

URICOECHEA, Fernando. O minotauro imperial. São Paulo: Difel, 1978.

WEFFORT, Francisco. O populismo na política brasileira. Rio de Janeiro: Paz e Terra, 1980. 